\section{Simplified apparatus for ultrafiltration by centrifugation}

\section{R. LEWIN From the Department of Chemical Pathology, Royal Free Hospital, London}

De Waard (1917) was the first to use centrifugal force for the process of ultrafiltration. Since then many improved methods have been devised, mainly as the result of developments in high speed centrifuges and commercially available semipermeable membranes. Supporting the membrane, however, has always given difficulty. Clegg (1949) supported a cellophane casing in a nylon bag within a glass centrifuge tube, but the method of attachment was tedious. In the method reported by Toribara, Terepka, and Dewey (1957), a sintered glass disc was used as the support. This method, however, required modified centrifuge cups, special glassware, and long periods of centrifugation for small yields of ultrafiltrate. Prasad and Flink (1957) used a narrow-meshed white gauze support for the Visking tubing containing serum but clinical gauze introduces highly fluorescent artifacts into the ultrafiltrate, and is therefore unsuitable for studies on plasma calcium fractions in which a fluorimetric assay procedure is used (Lewin, Wills, and Baron, 1969).

A simple and inexpensive ultrafiltration unit has been constructed using $30 \mathrm{ml}$ syringes and their cases $(30 \mathrm{ml}$ SE. 5-06117, Brunswick Corporation, Astronaut House, Hounslow, Middlesex). These syringes and their cases are made of rigid polypropylene. The syringe, of external diameter $26 \mathrm{~mm}$, fits closely inside the case, a cylindrical tube of internal diameter $27 \mathrm{~mm}$. The case is moulded with three interior supports upon which the syringe rests. Below the supports the case is tapered. The syringe case was prepared by cutting off the lid section to give a tapered plastic tube $110 \mathrm{~mm}$ in length. The plunger of the syringe was discarded and a $50 \mathrm{~mm}$ tubular section was cut from the body of the syringe. One end of this tubular section was heated on a hot plate until fully melted, then rapidly and firmly pressed on to a sheet of nylon gauze. This was left to set hard and the excess nylon and plastic trimmed off with a scalpel blade.

Received for publication 14 January 1969.
FIG. 1 A fully assembled ultrafiltration unit.

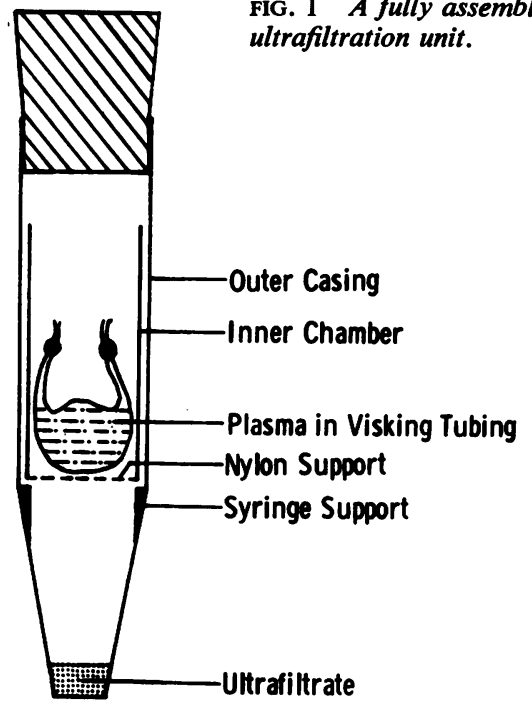

Visking tubing containing plasma was manipulated into the inner chamber until it rested upon the nylon gauze. This unit was then slid into the outer casing until it rested upon the three syringe supports. A fully assembled unit is shown in Figure 1.

The apparatus can be equilibrated with $5 \% \mathrm{CO}_{2}$ in oxygen (Prasad and Flink, 1957), then sealed with a rubber bung (no. 27). The inner unit prevents the bung from completely entering the tube during centrifugation.

Using this apparatus, we are able to obtain $0.5 \mathrm{ml}$ of protein-free ultrafiltrate from $5 \mathrm{ml}$ plasma, centrifuging for one hour at 2,500 rpm with a force of $1,000 \mathrm{~g}$.

This work was supported by a grant from the Endowment Fund of the Royal Free Hospital.

\section{REFERENCES}

Clegg, R. E. (1949). Chemist Analyst, 38, No. 4.

De Waard, D. J. (1917). Arch. néerl. Physiol., 2, 530.

Lewin, M. R., Wills, M. R., and Baron, D. N. (1969). J. clin. Path., 22, 222.

Prasad, A. S., and Flink, E. B. (1957). J. appl. Physiol., 10, 103.

Toribara, T. Y., Terepka, A. R., and Dewey, P. A. (1957). J. clin. Invest., 36, 738. 